\title{
Enhanced hypertension prevalence in non-Han Chinese minorities from Xinjiang Province, China
}

\begin{abstract}
Zhensui Lu ${ }^{1,2}$, Zhenhong $\mathrm{Lu}^{3}$, Yanling Zhu ${ }^{4}$, Zhaoyang Yan $^{5}$, Xiaoquan Liu ${ }^{4}$, Shigui Yan ${ }^{1,2}$ and Guo-Ping Shi ${ }^{6}$
Hypertension and its risk factors have been thoroughly investigated in multiple population studies, but little is known about Chinese minorities. In this study, we examined the association of hypertension prevalence with its risk factors in Han and nonHan minorities from Xinjiang Province, China, who have distinct lifestyles. A total of 9551 Han and non-Han Chinese (Han $83.9 \%$, non-Han $16.1 \%$ ) 17-81-years old participated in this clinical survey and anthropometric screening. Physical examination was performed on each participant, including measurement of systolic and diastolic blood pressure and body mass index (BMI). The prevalence of hypertension in non-Hans was found to be significantly greater than in Hans, in both men (39.92\% vs. $28.55 \%, P<0.001)$ and women $(19.49 \%$ vs. $10.29 \%, P<0.001)$ among the $36-55$-year old age group. BMI was also found to be significantly higher in non-Hans than Hans in men (BMI: $26.54 \pm 3.23$ vs. $24.82 \pm 2.77 \mathrm{~kg} \mathrm{~m}^{-2}, P<0.001$ ) and women (BMI: $26.92 \pm 3.20$ vs. $24.19 \pm 3.16 \mathrm{~kg} \mathrm{~m}^{-2}, P<0.001$ ) in the same age group, but not in those $<36$-years old. Although Han women had normal weights or were slightly overweight (age $>36, \mathrm{BMI}=22.25-24.19 \mathrm{~kg} \mathrm{~m}^{-2}$ ), non-Han women from the same age group were found to be severely overweight (ages $36-55, \mathrm{BMI}=24.94 \mathrm{~kg} \mathrm{~m}^{-2}$, ages $>56$, $B M I=26.92 \mathrm{~kg} \mathrm{~m}^{-2}$ ). A strong association between increased BMI and hypertension was shown in all ethnic and gender groups. The prevalence of hypertension in overweight (BMI $\geqslant 24 \mathrm{~kg} \mathrm{~m}^{-2}$ ) and obese (BMI $\geqslant 28 \mathrm{~kg} \mathrm{~m}^{-2}$ ), aged (36-81), male, and non-Han participants was significantly greater than in lean (BMI $<24 \mathrm{~kg} \mathrm{~m}^{-2}$ ), young (17-35), female Hans, after adjustment for these variables in a multivariate logistic regression analysis $(P<0.001)$. A high prevalence of hypertension in overweight and obese elderly non-Han men suggests that BMI, age, sex and race are important risk factors for hypertension in this Chinese population. Hypertension Research (2009) 32, 1097-1103; doi:10.1038/hr.2009.159; published online 25 September 2009
\end{abstract}

Keywords: body mass index; minority; risk factor

\section{INTRODUCTION}

Cardiovascular diseases (CVDs) remain the leading cause of death in major racial and ethnic groups worldwide. ${ }^{1}$ Hypertension is one of the most prevalent CVDs and affects certain ethnic groups disproportionately in China. ${ }^{2}$ For example, Kazakh people from Xinjiang Province have more rapid progression of hypertension than Hans from the same area. In a survey by the Chinese National Blood Pressure Survey Cooperative Group on the prevalence of hypertension in different ethnic groups in China in 1991, Kazakh men had the fifth highest and Kazakh women had the highest rates of hypertension among all ethnic groups in China, which was much higher than Hans. ${ }^{2}$ These observations suggest an important impact of ethnic-associated lifestyles and genetic factors on hypertension, a fact that is poorly recognized in China. The causes for these disparities are not fully understood, although we do know that Kazakh populations are generally overweight, have different dietary habits from Hans and have poor access to healthcare facilities. ${ }^{3}$ The paucity of information about the risk factors that affect blood pressure (BP) and the prevalence of hyperten- sion in these minorities hampers the development and implementation of specific CVD-prevention programs.

As one of the most frequent risk factors of hypertension, obesity is defined as an unhealthy excess of body fat. This metabolic disease is related to several chronic conditions, such as type 2 diabetes mellitus, hypertension, stroke and coronary artery disease. ${ }^{4}$ Anthropometric measures, such as body mass index (BMI), are common determinants of obesity in many epidemiological studies. BMI reflects total body fat in population health surveys, ${ }^{5}$ and obesity is defined according to certain criteria. ${ }^{6}$ In 2000, the World Health Organization (WHO) proposed a unified worldwide definition of the terms obese and overweight. However, compared with Western populations, Chinese people have a slender build, and 'conventional' definitions of obesity may not apply. Therefore, the WHO lowered BMI values to define overweight and obese people living in the Asia-Pacific region. ${ }^{7,8}$ For example, the criteria for defining an individual as overweight $\left(\geqslant 23.0 \mathrm{~kg} \mathrm{~m}^{-2}\right)$ or obese $\left(\geqslant 25 \mathrm{~kg} \mathrm{~m}^{-2}\right)$ are lower for Chinese people than for those living in Western countries $\left(\geqslant 25 \mathrm{~kg} \mathrm{~m}^{-2}\right.$ and

${ }^{1}$ Department of Orthopedic Surgery, Second Affiliated Hospital, Zhejiang University College of Medicine, Hangzhou, China; ${ }^{2}$ Orthopedic Research Institution, Zhejiang University, Hangzhou, China; ${ }^{3}$ Department of Internal Medicine, Xinjiang Petroleum College Hospital, Urumqi, China; ${ }^{4}$ Center for Medical Examination, Urumqi First People Hospital, Urumqi, China; ${ }^{5}$ Department of Internal Medicine, Xinjiang Industry College Hospital, Urumqi, China and ${ }^{6}$ Department of Medicine, Brigham and Women's Hospital, Harvard Medical School, Boston, MA, USA

Correspondence: Dr G-P Shi, Cardiovascular Medicine, Brigham and Women's Hospital, Harvard Medical School, NRB-7, 77 Avenue Louis Pasteur, Boston, MA 02115, USA. E-mail: gshi@rics.bwh.harvard.edu

Received 31 May 2009; revised 15 July 2009; accepted 9 August 2009; published online 25 September 2009 
$\geqslant 30 \mathrm{~kg} \mathrm{~m}^{-2}$, respectively). ${ }^{9}$ Earlier studies showed that the prevalence of hypertension, diabetes, dyslipidemia and their risk factors is associated with higher BMI. ${ }^{10}$ Although these observations were made in Chinese populations to identify individuals at high risk of CVD, to our knowledge, race-specific correlation studies between body fat distribution and CVDs such as hypertension have not been documented. For example, although it is generally accepted that BP differs among Chinese minorities, information on body fat composition or distribution and association with age and gender are lacking. Xinjiang Province is one of the unique provinces in China where multiple minorities have different lifestyles such as diet differences. Obesity and other risk factors among Xinjiang minorities and their association with hypertension prevalence are important, but remain largely unknown. We investigated whether the association of hypertension and the obesity risk factors, BMI, age, race and gender, differs between Han and non-Han Chinese minorities in this province, and whether age, race and gender influence this correlation.

\section{METHODS}

\section{Study population}

This study was a clinical survey-based study performed from March 2007 to February 2009 in the city of Urumqi, Xinjiang, China. A total of 9913 annual physical examination patients from three hospitals, including the Urumqi First People Hospital, Xinjiang Petroleum College Hospital, and Xinjiang Industry College Hospital, were randomly invited to participate in this study. All participants first completed a clinical survey questionnaire consisting of age, gender, race, education level, origin, occupation, employment status; a health history, including hypertension, diabetes, alcohol consumption and smoking; various medical examinations, including electrocardiogram, chest X-ray and ultrasound; and the use of BP medications for hypertension. Participants who were pregnant or lacked complete anthropometrical data were excluded before further evaluation. The remaining subjects $(n=9551)$ consisted of 8012 Hans (83.89\%) and 1539 non-Hans (16.11\%), with $58.1 \%$ men and $41.9 \%$ women, from 17 to 81 years of age. Non-Hans include Uygur $(n=833)$, Kazakh $(n=578)$, Hui $(n=116)$, Shi $(n=3)$, Mongolian $(n=3)$, Man $(n=3)$, Miao $(n=2)$ and Zhuang $(n=1)$. Besides the participants taking hypertension medicine, no subjects were taking any other medication. A complete physical examination was performed on each selected participant, including measurement of systolic blood pressure (SBP) and diastolic blood pressure (DBP) and calculation of BMI. The Ethical Committee of each participating hospital approved this study.

\section{Anthropometric measurements}

Anthropometric measurements (height and weight) were recorded with standardized protocols. Body weight was measured with participants wearing light clothing on a calibrated balance beam scale. BMI was used to determine whether a subject was overweight or obese and was calculated by the following formula: $\mathrm{BMI}=$ (weight in kilograms)/(height in meters $)^{2}$. BP was measured in each participant's right arm (with the subject in a sitting position after $5 \mathrm{~min}$ of bed rest) with a mercury sphygmomanometer and an appropriately sized cuff.

\section{Criteria for obesity and hypertension}

According to WHO standards, participants with a BMI $\left(\mathrm{kg} \mathrm{m}^{-2}\right)<24.0$ were considered to be within normal range. Those with a BMI of 24.0-27.9 were considered overweight and at risk for obesity. Subjects with a BMI $\geqslant$ 28.0 were considered obese. ${ }^{7,8}$ Subjects with an $\mathrm{SBP} \geqslant 140 \mathrm{~mm} \mathrm{Hg}$ and/or $\mathrm{DBP} \geqslant 90 \mathrm{~mm} \mathrm{Hg}$ or who had taken antihypertension medications within the past 2 weeks were considered hypertensive. ${ }^{11}$

\section{Statistical analysis}

All data were entered in the Statistical Package for the Social Sciences Windows software (SPSS Chicago, IL, USA). Pearson's $\chi^{2}$ test was used to examine the hypertension prevalence rate among different genders, ages and ethnicities. One-way analysis of variance and an independent samples $t$-test were used to determine the differences in BMI $\left(\mathrm{kgm}^{-2}\right)$ between Han and non-Han participants and the correlation of BMI with hypertension and non-hypertension in different race, age and gender groups. Pearson's correlation coefficient test (two-tailed test of significance) was used to examine the relationship among SBP, DBP and BMI as continuous variables. Bivariate analysis of factor modeling ( $\chi^{2}$ test) estimated the probability of unadjusted odds ratio (OR) of hypertension stratified for BMI, age, race and gender. Multivariate logistic regression was used to determine the association between BP and risk factors for hypertension after adjustment for other confounders and stratification for gender, age and race. $P<0.05$ was considered statistically significant.

\section{RESULTS}

Hypertension prevalence in different age, gender and race groups To simplify the comparison, we grouped the participants into three age groups: old (56-81 years), middle-aged (36-55) and young (17-35). Owing to our small sample size $(n=1538)$ for the multiple minorities in this study, we grouped all eight minorities into one 'nonHan' category. Older subjects had generally higher hypertension prevalence than the younger volunteers. Among the three age groups, the old group followed by the middle-aged group had the highest hypertension prevalence rates in both the Han and non-Han groups. The young group had the lowest prevalence (Table 1).

Gender was also shown to influence the prevalence of hypertension. In the young (17-35) and middle-aged (36-55) groups, males had significantly higher prevalence rates than females among both Hans and non-Hans (Table 1). Among old subjects, male Hans still had significantly higher hypertension prevalence rates than females, but this significance disappeared in non-Hans, that is, old non-Han subjects had similar hypertension prevalence rates in both men and women. Importantly, non-Han subjects from this age group had the highest hypertension prevalence rates for both males and females among all age or ethnic groups, suggesting that hypertension is a common public health problem among the elderly non-Han population in this area of China.

In addition to age and gender, we found that on grouping all Uygur, Kazakh, Hui, Shi, Mongolian, Man, Miao and Zhuang subjects together as non-Han, these subjects as a whole had significantly higher hypertension prevalence rates than Hans in all three age groups. When we subgrouped Han and non-Han subjects into males and females, we also found that non-Hans of both genders had significantly higher hypertension prevalence rates than Hans in all three age groups, except for females in the 17-35 age group, which did not reach statistical significance (Table 1). Limited subject numbers did not allow us to examine whether each of these minority groups alone had a hypertension rate different from that of Hans, but we were able to perform the Pearson's $\chi^{2}$ test to compare Hans with both Uygurs and Kazakhs. As shown in Table 2, Kazakhs had a greater rate of hypertension than Uygurs, and both had greater hypertension rates than Hans among all tested age groups, although some differences did not reach statistical significance (old male Kazakhs vs. Hans and middle-aged male Uygurs vs. Hans) (Table 2). Similar to Hans, Uygur and Kazakh males had significantly greater hypertension prevalence rates than females in both the 17-35 and 36-55 age groups. Such significance disappeared in the elderly (56-81) group (Table 2).

\section{Increased body weight in non-Hans}

As one of the most common criteria for obesity, BMI is closely associated with the risk of coronary heart disease and type 2 diabetes in the Chinese population. ${ }^{12}$ On the basis of BMI standard definitions of overweight $\left(\geqslant 24 \mathrm{~kg} \mathrm{~m}^{-2}\right)$ and obese $\left(\geqslant 28 \mathrm{~kg} \mathrm{~m}^{-2}\right)$ for Chinese 
Table 1 Hypertension prevalence rate (\%) among Han and Non-Han Chinese

\begin{tabular}{|c|c|c|c|c|c|c|}
\hline \multirow[b]{2}{*}{ Age } & \multirow[b]{2}{*}{ Gender } & \multicolumn{2}{|c|}{ Han } & \multicolumn{2}{|c|}{ Non-Han } & \multirow[b]{2}{*}{ P-value } \\
\hline & & $\mathrm{n} / \mathrm{N}$ & $\%$ & $\mathrm{n} / \mathrm{N}$ & $\%$ & \\
\hline \multirow[t]{4}{*}{$17-35$} & Male & $260 / 2761$ & 9.42 & $104 / 602$ & 17.28 & $<0.001$ \\
\hline & Female & $22 / 2034$ & 1.08 & $8 / 370$ & 2.16 & 0.085 \\
\hline & All & $282 / 4795$ & 5.88 & $112 / 972$ & 11.52 & $<0.001$ \\
\hline & $P$-value ${ }^{* *}$ & & $<0.001$ & & $<0.001$ & \\
\hline \multirow[t]{4}{*}{$36-55$} & Male & $402 / 1407$ & 28.55 & $95 / 238$ & 39.92 & $<0.001$ \\
\hline & Female & $111 / 1079$ & 10.29 & $38 / 195$ & 19.49 & $<0.001$ \\
\hline & All & $513 / 2486$ & 20.63 & $133 / 433$ & 30.72 & $<0.001$ \\
\hline & $P$-value ${ }^{* *}$ & & $<0.001$ & & $<0.001$ & \\
\hline \multirow[t]{4}{*}{$56-81$} & Male & $233 / 462$ & 50.43 & $50 / 77$ & 64.94 & $<0.001$ \\
\hline & Female & $106 / 269$ & 39.41 & $37 / 56$ & 66.07 & $<0.001$ \\
\hline & All & $339 / 731$ & 46.37 & $87 / 133$ & 65.41 & $<0.001$ \\
\hline & $P$-value ${ }^{* *}$ & & 0.004 & & 0.892 & \\
\hline \multirow[t]{4}{*}{ Total } & Male & $895 / 4630$ & 19.33 & 249/917 & 27.15 & $<0.001$ \\
\hline & Female & 239/3382 & 7.07 & $83 / 621$ & 13.37 & $<0.001$ \\
\hline & All & $1134 / 8012$ & 14.15 & $332 / 1538$ & 21.59 & $<0.001$ \\
\hline & $P$-value** & & $<0.001$ & & $<0.001$ & \\
\hline
\end{tabular}

Abbreviations: $n$, subjects with hypertension; $N$, total subjects.

*Pearson $\chi^{2}$ test compared with Han.

**Pearson $\chi^{2}$ test comparison between males and females.

Table 2 Hypertension prevalence rate (\%) in Han, Uygur and Kazak subgroups

\begin{tabular}{|c|c|c|c|c|c|c|}
\hline Age (year) & Gender & Han & Uygur & P-value* & Kazak & P-value* \\
\hline & Male & $\begin{array}{l}9.42 \\
(n=2761)\end{array}$ & $\begin{array}{l}12.36 \\
(n=283)\end{array}$ & 0.111 & $\begin{array}{l}21.63 \\
(n=296)\end{array}$ & $<0.001$ \\
\hline \multirow[t]{3}{*}{$17-35$} & Female & $\begin{array}{l}1.08 \\
(n=2034)\end{array}$ & $\begin{array}{l}0.70 \\
(n=201)\end{array}$ & 0.910 & $\begin{array}{l}3.55 \\
(n=115)\end{array}$ & 0.006 \\
\hline & $P$-value ${ }^{* *}$ & $<0.001$ & $<0.001$ & & $<0.001$ & \\
\hline & Male & $\begin{array}{l}28.55 \\
(n=1407)\end{array}$ & $\begin{array}{l}33.78 \\
(n=148)\end{array}$ & 0.182 & $\begin{array}{l}58.90 \\
(n=65)\end{array}$ & $<0.001$ \\
\hline \multirow[t]{3}{*}{$36-55$} & Female & $\begin{array}{l}10.29 \\
(n=1079)\end{array}$ & $\begin{array}{l}17.19 \\
(n=128)\end{array}$ & 0.018 & $\begin{array}{l}28.57 \\
(n=49)\end{array}$ & 0.001 \\
\hline & $P$-value** & $<0.001$ & 0.002 & & 0.001 & \\
\hline & Male & $\begin{array}{l}50.43 \\
(n=462)\end{array}$ & $\begin{array}{l}70.45 \\
(n=44)\end{array}$ & 0.011 & $\begin{array}{l}53.57 \\
(n=28)\end{array}$ & 0.428 \\
\hline \multirow[t]{3}{*}{$56-81$} & Female & $\begin{array}{l}39.41 \\
(n=269)\end{array}$ & $\begin{array}{l}65.52 \\
(n=29)\end{array}$ & 0.007 & $\begin{array}{l}71.19 \\
(n=25)\end{array}$ & 0.006 \\
\hline & $P$-value ${ }^{* *}$ & & 0.004 & 0.657 & 0.471 & \\
\hline & Male & $\begin{array}{l}19.33 \\
(n=4630)\end{array}$ & $\begin{array}{l}24.42 \\
(n=475)\end{array}$ & 0.008 & $\begin{array}{l}30.09 \\
(n=389)\end{array}$ & $<0.001$ \\
\hline \multirow[t]{2}{*}{ Total } & Female & $\begin{array}{l}7.07 \\
(n=3382)\end{array}$ & $\begin{array}{l}12.01 \\
(n=358)\end{array}$ & 0.001 & $\begin{array}{l}15.21 \\
(n=189)\end{array}$ & $<0.001$ \\
\hline & $P$-value ${ }^{* *}$ & $<0.001$ & $<0.001$ & & $<0.001$ & \\
\hline
\end{tabular}

*Pearson $\chi^{2}$ test to compare Hans.

** Pearson $\chi^{2}$ test to compare males and females.

Subject numbers are indicated in the parentheses.

people, ${ }^{7}$ we found that the mean BMI for non-Han men in the middle-aged $\left(B M I=25.91 \pm 3.29 \mathrm{~kg} \mathrm{~m}^{-2}\right)$ and old $(\mathrm{BMI}=26.54 \pm$ $3.23 \mathrm{~kg} \mathrm{~m}^{-2}$ ) groups reached the cutoff value for overweight. The
Table 3 BMI $\left(\mathrm{kg} \mathrm{m}^{-2}\right)$ in different age and gender groups from Han and Non-Han Chinese

\begin{tabular}{|c|c|c|c|c|c|c|}
\hline \multirow[b]{2}{*}{$\begin{array}{l}\text { Age } \\
\text { (year) }\end{array}$} & \multirow[b]{2}{*}{ Gender } & \multicolumn{2}{|r|}{ Han } & \multicolumn{2}{|c|}{ Non-Han } & \multirow[b]{2}{*}{ P-value* } \\
\hline & & $n$ & $\begin{array}{c}B M I \\
\text { (mean } \pm \text { s.d.) }\end{array}$ & $n$ & $\begin{array}{c}B M I \\
(\text { mean } \pm \text { s.d.) }\end{array}$ & \\
\hline \multirow[t]{3}{*}{$17-35$} & Male & 2761 & $21.67 \pm 2.93$ & 602 & $21.51 \pm 2.86$ & 0.221 \\
\hline & Female & 2034 & $20.12 \pm 2.30$ & 370 & $20.26 \pm 2.57$ & 0.263 \\
\hline & All & 4795 & $21.01 \pm 2.79$ & 972 & $21.03 \pm 2.82$ & 0.804 \\
\hline \multirow[t]{3}{*}{$36-55$} & Male & 1407 & $24.83 \pm 2.82$ & 238 & $25.91 \pm 3.29$ & $<0.001$ \\
\hline & Female & 1079 & $22.25 \pm 2.77$ & 195 & $24.94 \pm 3.91$ & $<0.001$ \\
\hline & All & 2486 & $23.71 \pm 3.07$ & 433 & $25.47 \pm 3.61$ & $<0.001$ \\
\hline \multirow[t]{3}{*}{$56 \sim 81$} & Male & 462 & $24.82 \pm 2.77$ & 77 & $26.54 \pm 3.23$ & $<0.001$ \\
\hline & Female & 269 & $24.19 \pm 3.16$ & 56 & $26.92 \pm 3.20$ & $<0.001$ \\
\hline & All & 731 & $24.59 \pm 2.93$ & 133 & $26.70 \pm 3.21$ & $<0.001$ \\
\hline \multirow[t]{3}{*}{ Total } & Male & 4630 & $22.94 \pm 3.27$ & 917 & $23.07 \pm 3.71$ & $<0.001$ \\
\hline & Female & 3382 & $21.12 \pm 2.86$ & 621 & $22.33 \pm 4.03$ & $<0.001$ \\
\hline & All & 8012 & $22.17 \pm 3.23$ & 1538 & $22.77 \pm 3.85$ & $<0.001$ \\
\hline
\end{tabular}

*One-way analysis of variance test.

BMI values for non-Han women in both the middle-aged $\left(B M I=24.94 \pm 3.91 \mathrm{~kg} \mathrm{~m}^{-2}\right)$ and old $\left(B M I=26.92 \pm 3.20 \mathrm{~kg} \mathrm{~m}^{-2}\right)$ groups also reached the cutoff value for overweight. In contrast, Han women and men in these age groups were significantly leaner than non-Han women and men, although the mean BMI values of Han men from both the middle-aged $\left(B M I=24.83 \pm 2.82 \mathrm{~kg} \mathrm{~m}^{-2}\right)$ and old $\left(\mathrm{BMI}=24.82 \pm 2.77 \mathrm{~kg} \mathrm{~m}^{-2}\right.$ ) groups also reached the cutoff values for overweight. The mean BMI of Han females in the old age group reached just above the overweight cutoff value $(\mathrm{BMI}=24.19 \pm 3.16)$ and those in the middle-aged group remained slim (BMI= $22.25 \pm 2.77)$. With the same standard, all young Han and non-Han men and women 17-35 were lean (Table 3 ).

Increased BMI in subjects with hypertension

Patients with high BMIs can have a high risk of CVD. Non-Han men and women had greater BMI values and higher prevalence rates of hypertension than Han men and women, particularly among middleaged and old subjects (see Tables 1-3), suggesting a correlation between BMI and hypertension. When we grouped all participants according to hypertension status, we found that those with hypertension, regardless of their gender or race, had significantly higher BMI values than those without hypertension (Table 4). On the basis of the standard cutoff values, all hypertensive subjects were overweight (BMI $>24 \mathrm{~kg} \mathrm{~m}^{-2}$ ), whereas all non-hypertensive participants were lean (BMI $<23 \mathrm{~kg} \mathrm{~m}^{-2}$ ). Among male subjects with or without hypertension, race did not significantly affect BMI. By contrast, female non-Hans had significantly greater BMIs than female Hans in both the hypertension and non-hypertension groups. Among the same ethnic groups, males generally had higher BMI values than females, except non-Han females who had hypertension (Table 4). Therefore, hypertension, race and gender are all associated with BMI.

\section{Correlation coefficient and significance of BMI with BP in Hans} and non-Hans

The significant impact of hypertension status on BMI suggests their close association. In this study, hypertension was defined as $\mathrm{SBP} \geqslant 140 \mathrm{~mm} \mathrm{Hg}$ and/or DBP $\geqslant 90 \mathrm{~mm} \mathrm{Hg}$ and/or use of antihyper- 
Table 4 BMI and hypertension prevalence in different gender and ethnic groups

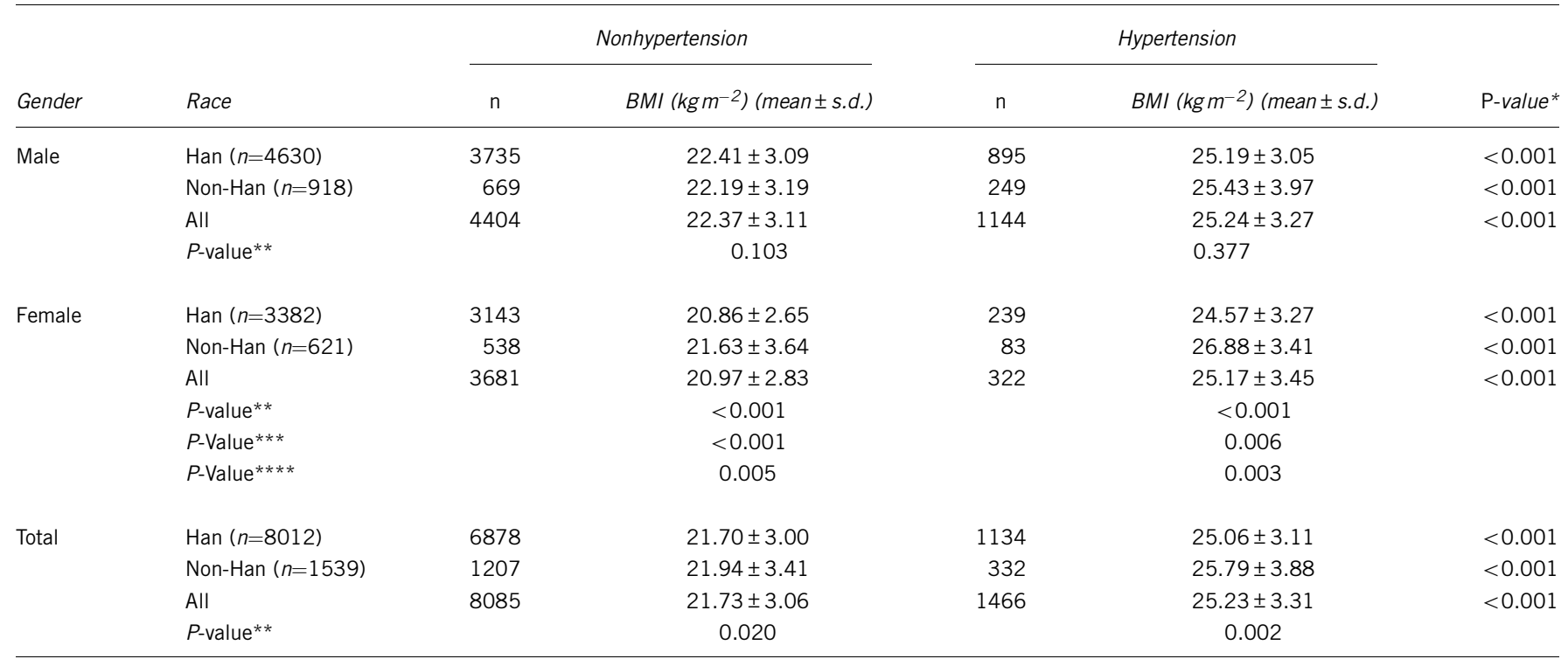

*Independent samples $t$-test when compared between hypertension and non-hypertension.

** independent samples $t$-test to compare Hans and non-Hans.

*** independent samples $t$-test to compare males and females in Han.

$* * * *$ independent samples $t$-test to compare males and females in non-Hans.

tension medication within the past 2 weeks. Therefore, we performed Pearson's correlation coefficient test to examine whether BMI correlates with SBP or DBP as continuous variables. In both Hans and nonHans, BMI correlated with both SBP and DBP. This trend holds true for both males and females and for subjects grouped into hypertension or non-hypertension categories (Table 5). For unknown reasons, we found that the correlation coefficient values between BMI and SBP or DBP were greater in females than in males (Table 5).

BMI, age, race and gender are important risk factors for hypertension

Using the bivariate analysis of factors $\chi^{2}$ test, we showed that hypertension prevalence correlated with BMI, age, race and gender. Among all 9551 participants, $20.26 \%$ of hypertensive subjects were obese, whereas only $3.29 \%$ of non-hypertensive subjects were obese $(P<0.001)$. The unadjusted OR reached 13.60 among obese subjects. Therefore, obese subjects had a 13.60-fold higher risk of developing hypertension than lean subjects. Overweight subjects showed a similar trend toward hypertension, and had a 5.13-fold higher risk of developing hypertension than lean subjects (Table 6).

Similar to BMI, age was another important risk factor for hypertension. Among 1466 hypertensive subjects, $29.06 \%$ were 56-81-years old and $44.07 \%$ were 36-55-years old. By contrast, most of the non-hypertensive subjects $(66.77 \%)$ were in the young population (17-35 years). Only $5.41 \%$ of the non-hypertensive subjects were 5681 and $28.13 \%$ were $36-55$-years old. The unadjusted OR values of the 56-81 group and the 36-55 group were much higher than that of the 17-35 group (Table 6), suggesting that aged populations have a greater risk of developing hypertension than younger populations. With much smaller OR values, race and sex were also important risk factors of hypertension. Non-Hans had a 1.67-fold higher risk of hypertension than Hans. Fewer women than men had hypertension $(\mathrm{OR}=0.34)$ (Table 6).

Similar findings were obtained after adjustment for confounders, such as BMI, age, race and gender. In a logistic regression analysis model for multivariate factors, after adjusting for age, race and gender, we found that both obese $(\mathrm{OR}=6.05)$ and overweight $(\mathrm{OR}=2.73)$
Table 5 Pearson correlation coefficient $(r)$ and significance between blood pressures (SBP or DBP) of different genders or hypertension status and BMI of different races

\begin{tabular}{|c|c|c|c|c|c|}
\hline \multirow{2}{*}{$\begin{array}{l}\text { Gender or } \\
\text { hypertension status }\end{array}$} & \multirow{2}{*}{$\begin{array}{l}\text { Blood } \\
\text { pressure }\end{array}$} & \multicolumn{2}{|c|}{$\begin{array}{c}\text { BMI } \\
\left(\mathrm{kgm}^{-2}\right) \text { of Han }\end{array}$} & \multicolumn{2}{|c|}{$\begin{array}{c}\text { BMI } \\
\left(\mathrm{kgm}^{-2}\right) \text { of non-Han }\end{array}$} \\
\hline & & $r$ & $\mathrm{P}$-value & $r$ & P-value \\
\hline \multirow[t]{2}{*}{ Male } & SBP & 0.325 & $<0.001$ & 0.380 & $<0.001$ \\
\hline & DBP & 0.364 & $<0.001$ & 0.351 & $<0.001$ \\
\hline \multirow[t]{2}{*}{ Female } & SBP & 0.411 & $<0.001$ & 0.503 & $<0.001$ \\
\hline & DBP & 0.386 & $<0.001$ & 0.495 & $<0.001$ \\
\hline \multirow[t]{2}{*}{ Hypertension } & SBP & 0.099 & 0.001 & 0.265 & $<0.001$ \\
\hline & DBP & 0.177 & $<0.001$ & 0.210 & $<0.001$ \\
\hline \multirow[t]{2}{*}{ Nonhypertension } & SBP & 0.299 & $<0.001$ & 0.247 & $<0.001$ \\
\hline & DBP & 0.291 & $<0.001$ & 0.190 & $<0.001$ \\
\hline \multirow[t]{2}{*}{ Total } & SBP & 0.416 & $<0.001$ & 0.444 & $<0.001$ \\
\hline & DBP & 0.432 & $<0.001$ & 0.422 & $<0.001$ \\
\hline
\end{tabular}

subjects had a much greater risk of hypertension than lean subjects. Similarly, old subjects (age 56-81) had an OR of 5.01 for hypertension compared with young subjects (17-35). Decreasing the age range to 36-55 reduced the OR to 2.04 (Table 6). Similar to the unadjusted analysis in this study, non-Hans $(\mathrm{OR}=1.68)$ remained at greater risk for hypertension than Hans. Again, men tended to have a higher risk of hypertension than women after adjustment for BMI, age and race (Table 6).

\section{DISCUSSION}

This study provides detailed analysis of hypertension prevalence rates and its risk factors, including body weight, age, gender and race, in 
Table 6 Unadjusted and adjusted odds ratio of hypertension and risk factors BMI, age, race and gender

\begin{tabular}{|c|c|c|c|c|}
\hline Variables & Nonhypertension (\%) & Hypertension (\%) & Unadjusted OR $(95 \% \mathrm{Cl})^{*}$ & Adjusted OR $(95 \% \mathrm{Cl})^{* * *}$ \\
\hline \multicolumn{5}{|l|}{$B M I\left(\mathrm{~kg} \mathrm{~m}^{-2}\right)$} \\
\hline Normal $(<24)$ & 92.41 & 7.59 & 1.00 & 1.00 \\
\hline Obese $(\geqslant 28)$ & 47.25 & 52.75 & $13.60(11.27-16.42)^{\#}$ & $6.05(4.93-7.43)^{\#}$ \\
\hline \multicolumn{5}{|l|}{ Age (year) } \\
\hline $55-81$ & 50.69 & 49.31 & $13.26(11.21-15.69)^{\#}$ & $5.01(3.06-8.21)^{\#}$ \\
\hline \multicolumn{5}{|l|}{ Race } \\
\hline Han & 85.85 & 14.15 & 1.00 & 1.00 \\
\hline Non-Han & 78.41 & 21.59 & $1.67(1.46-1.92)^{\#}$ & $1.68(1.43-1.97)^{\#}$ \\
\hline
\end{tabular}

*Bivariate analysis of factors ( $\chi^{2}$ test).

**Logistic regression analysis of multivariate factors. Adjusted variates age, race, gender and $\mathrm{BMI}$. $\mathrm{Cl}$, confidence interval.

$\# P$ value $<0.001$

a population from Xingjiang Province, China, where multiethnic groups of Chinese live. Non-Han, male, overweight or older subjects appeared to have a much greater prevalence of hypertension than Han, female, lean or young subjects. In general, our observations agree with many earlier studies that found that weight control may reduce the incidence of hypertension. ${ }^{13}$ We also found that hypertension prevalence correlates positively with age, ${ }^{14}$ and men may have a greater risk of hypertension than women. ${ }^{15,16}$

Earlier studies showed that age is one of the most significant risk factors for CHD. Patients in their 70s have more than 10 times the risk of developing CHD than those in their $30 \mathrm{~s}^{17}$ We also showed that age constitutes an important risk factor of hypertension in this Chinese population study. Even after adjusting for gender, BMI and race, those aged 56 years and older had a $>5$-fold risk of hypertension compared with those aged 35 years and younger (Table 6). The effect of gender on hypertension has been controversial. Our study and many others suggested that males tend to have a greater risk of hypertension than females. ${ }^{15,16}$ By contrast, many other studies have suggested that females seem to have higher prevalence rates of hypertension than males. ${ }^{18-20}$ Therefore, race, lifestyle and environment may influence this conclusion.

Obesity, a rapidly growing health problem, is one of the major risk factors of CVD in developed and even developing countries. ${ }^{21}$ Women with a BMI of $29-30 \mathrm{~kg} \mathrm{~m}^{-2}$ have a three-fold higher risk of heart disease than lean women. ${ }^{21}$ Although we cannot change our age, race and gender, we can manage weight and obesity. In this study, being overweight or obese seemed to constitute major risk factors for hypertension in this Chinese population. The unadjusted OR of obese subjects with hypertension reached 13.60, and the adjusted OR remained as high as 6.05 .

We still found more than a two-fold reduction in OR among those who were overweight before and after adjustment. Therefore, BMI values served as an important hallmark not only for obesity, but also for hypertension and possibly other CVDs, at least in this Chinese population.

In the United States, the age-adjusted prevalence of hypertension was $40.5 \%$ among non-Hispanic blacks and only $27.4 \%$ among nonHispanic whites, according to a survey in 2005 by the National Center for Chronic Disease Prevention and Health Promotion, Centers for Disease Control and Prevention. Similar to our findings in this study, race can be a significant risk factor for hypertension. Hans and nonHans in Xinjiang Province often follow different lifestyles, which may lead, in part, to increased body weight and the higher prevalence of hypertension in non-Hans compared with Hans. Earlier studies suggested that dietary habits, genetics and sedentary lifestyles are closely related to hypertension. ${ }^{22-24}$ For example, Uygur and Kazakh people derive $32 \%$ of their calorie intake from red meat, which is twice as much as Hans consume. Further, Uygur and Kazakh people consume much more salt and fewer vegetables and fruits than do Hans. Minority communities typically have several important dietary alterations, such as increased sodium consumption and reduced potassium and calcium intake. The high intake of dietary sodium has been linked to the high prevalence of hypertension. ${ }^{25,26}$ For example, the recommended daily allowance of sodium intake is $0.5-1.0 \mathrm{~g}$ per day, but the current Chinese population consumes five times more than that, especially in the minority communities. ${ }^{27}$ Potassium intake has the opposite effect on hypertension, that is, there is an inverse relationship between potassium intake and hypertension, but minorities consume diets low in potassium. ${ }^{28}$ The Dietary Approaches to Stop Hypertension (DASH) trial tested the potential benefit of diets rich in potassium and low in sodium, saturated fat, total fat and cholesterol in patients with known hypertension. ${ }^{29,30}$ The DASH diet especially benefitted hypertension patients with high sodium intake. An increase of potassium intake from $1.7 \mathrm{~g}$ per day to $4.1 \mathrm{~g}$ per day, with a corresponding decrease in sodium consumption, reduced BP by $\sim 12 \mathrm{~mm} \mathrm{Hg} .{ }^{31}$ Elliott et al. ${ }^{32}$ emphasized that vegetable protein intake inversely relates to BP. A healthy lifestyle aimed at preventing high BP and related diseases needs to include a diet high in vegetables. Decreasing saturated, polyunsaturated and unsaturated fat intake and replacing these fats with monounsaturated fats more effectively controls body weight gain and hypertension than does merely decreasing total fat intake. $^{33,34}$ These data highlight the potential to reduce CVD in the minority community by effective control of body weight and dietary adjustments. Therefore, both men and women should increase their intake of fruits, vegetables and fiber to decrease their risk for CVD; such dietary practices should form the cornerstone of any CVD-prevention program. 
Our study has several limitations. It included 1538 non-Han subjects from at least eight different minorities. Increased prevalence of hypertension in non-Han $v s$. Han subjects may not apply to all eight minorities. The relatively small sample sizes of the non-Han subjects in this study limited the power of our analysis for each individual minority. Thus, analyzing a certain minority group or making any conclusion regarding hypertension prevalence among respective Chinese minorities would prove not only difficult but also inaccurate. This is particularly true for the Hui, Shi, Mongolian, Man, Miao and Zhuang subgroups, for which we cannot perform independent analysis. It has also been shown in many studies that alcohol consumption and smoking are obvious confounders for hypertension or other CVD. However, incomplete information on alcohol consumption and smoking in this study did not allow us to include these confounders in the OR analysis shown in Table 6. Exclusion of these confounders may impact the OR values of other variables listed in the Table. Besides the insufficient numbers of non-Han subjects and the missing subject information, this study also has subject selection and information bias. All participants were volunteers from a group of hospital visitors, which may affect the representativity of this study. The definition of hypertension may also lead to information bias. In addition to subjects who had SBP $\geqslant 140 \mathrm{mmHg}$ and/or $\mathrm{DBP} \geqslant 90 \mathrm{~mm} \mathrm{Hg}$, subjects who had taken antihypertension medications within the past 2 weeks were also considered hypertensive. It is possible that some of these patients may no longer have hypertension.

Social, physiological and genetic variations in the minority community may also affect CVD. ${ }^{35}$ Although we have showed an association between body fat deposition and hypertension in both the Han and non-Han subjects, further study is needed to understand the contribution of dietary habits, genetic background and other lifestyle differences to blood lipoprotein levels, obesity and associated CVD. ${ }^{36,37}$ The cause of hypertension and the percentage of obese and overweight people could vary from region to region. Education level, employment status, dietary habits, socioeconomic disparities, medical care plan and local environmental factors may also account for the association between BMI and hypertension. ${ }^{38}$ Therefore, further investigations are necessary to explore these possibilities. Given the recent identification of candidate genes that mediate hypertension, such as those involved in the formation of extracellular matrix proteins and lipid metabolism, ${ }^{39}$ these genetic factors may have critical, but thus far unrecognized, functions in the observed ethnic differences in the development of hypertension. All of these genetic characterizations, population studies and biochemical analyses suggest that maintaining optimal body weight constitutes an important step toward reducing hypertension risk, an assumption that probably holds true for all populations regardless of their nationalities.

\section{CONFLICT OF INTEREST}

The authors declare no conflict of interest.

\section{ACKNOWLEDGEMENTS}

This study is partially supported by grants from the American Heart Association (0840118N to GPS) and the NIH (HL60942, HL67283 and HL81090 to GPS). We thank Dr Junfang Wang from the Department of Epidemiology and Health Statistics, Zhejiang University College of Medicine, for her assistance in the statistical analysis.

1 Liao Y, McGee DL, Cooper RS. Prediction of coronary heart disease mortality in blacks and whites: pooled data from two national cohorts. Am J Cardiol 1999; 84: 31-36.
2 People's Republic of China National Blood Pressure Survey Cooperative Group. A survey on the prevalence of hypertension in different ethnic groups in China. Chin J Hypertens 1995; 3: 24-30.

3 Smith Jr SC, Clark LT, Cooper RS, Daniels SR, Kumanyika SK, Ofili E, Quinones MA, Sanchez EJ, Saunders E, Tiukinhoy SD. American Heart Association Obesity, Metabolic Syndrome, and Hypertension Writing Group. Discovering the full spectrum of cardiovascular disease: Minority Health Summit 2003: report of the Obesity, Metabolic Syndrome, and Hypertension Writing Group. Circulation 2005; 111: e134-e139.

4 Siervogel RM, Wisemandle W, Maynard LM, Guo SS, Chumlea WC, Towne B. Lifetime overweight status in relation to serial changes in body composition and risk factors for cardiovascular disease: The Fels Longitudinal Study. Obes Res 2000; 8: 422-430.

5 Wang Y, Rimm EB, Stampfer MJ, Willett WC, Hu FB. Comparison of abdominal adiposity and overall obesity in predicting risk of type 2 diabetes among men. Am J Clin Nutr 2005; 81: 555-563.

6 Zhou BF, Wu YF, Yang J, Li Y, Zhang HY, Zhao LC. Overweight is anindependent risk factor for cardiovascular disease in Chinese populations. Obes Rev 2002; 3: 147-156.

7 World Health Organization. The Asia-Pacific Perspective: Redefining Obesity and its Treatment. World Health Organization: Geneva, Switzerland, 2000. http://www.who.int/ bmi/index.jsp?introPage=intro_3.html.

8 WHO Expert Consultation. Appropriate body-mass index for Asian populations and its implications for policy and intervention strategies. Lancet 2004; 363: 157-163.

9 Zhou BF. Cooperative Meta-Analysis Group of the Working Group on Obesity in China. Predictive values of body mass index and waist circumference for risk factors of certain related diseases in Chinese adults-study on optimal cut-off points of body mass index and waist circumference in Chinese adults. Biomed Environ Sci 2002; 15: 83-96.

10 Zhou BF. Predictive values of body mass index and waist circumference for risk factors of certain related disease in Chinese adults: study on optimal cut-off points of body mass index and waist circumference in Chinese adults. Asia Pac J Clin Nutr 2002; 11: S685-S693.

11 Joint National Committee. The seventh report of the Joint National Committee on prevention, detection, evaluation and treatment of high blood pressure (JNC-7). JAMA 2003; 289: 2560-2571.

12 Manson JE, Colditz GA, Stampfer MJ, Willett WC, Rosner B, Monson RR, Speizer FE, Hennekens $\mathrm{CH}$. A prospective study of obesity and risk of coronary heart disease in women. N Engl J Med 1990; 322: 882-889.

$13 \mathrm{He} \mathrm{J}$, Whelton PK, Appel LJ, Charleston J, Klag MJ. Long-term effects of weight loss and dietary sodium reduction on incidence of hypertension. Hypertension 2000; 35: 544-549.

14 Pan WH, Nanas S, Dyer A, Liu K, McDonald A, Schoenberger JA, Shekelle RB, Stamler $\mathrm{R}$, Stamler J. The role of weight in the positive association between age and blood pressure. Am J Epidemiol 1986; 124: 612-623.

15 Kawabe H, Saito I. Influence of age and sex on prevalence of masked hypertension determined from home blood pressure measurements. J Hum Hypertens 2007; 21: 94-95.

16 Tohme RA, Jurjus AR, Estephan A. The prevalence of hypertension and its association with other cardiovascular disease risk factors in a representative sample of the Lebanese population. J Hum Hypertens 2005; 19: 861-868.

17 Zylberstein DE, Bengtsson C, Björkelund C, Landaas S, Sundh V, Thelle D, Lissner L. Serum homocysteine in relation to mortality and morbidity from coronary heart disease: a 24-year follow-up of the population study of women in Gothenburg. Circulation 2004; 109: 601-606.

18 Hajjar I, Kotchen TA. Trends in prevalence, awareness, treatment, and control of hypertension in the United States, 1988-2000. JAMA 2003; 290: 199-206.

19 Ostchega Y, Carroll M, Prineas RJ, McDowell MA, Louis T, Tilert T. Trends of elevated blood pressure among children and adolescents: data from the National Health and Nutrition Examination Survey1988-2006. Am J Hypertens 2009; 22: 59-67.

20 Sprafka JM, Bender AP, Jagger HG. Prevalence of hypertension and associated risk factors among diabetic individuals. The Three-City Study. Diabetes Care 1988; 11: 17-22.

21 Caterson ID, Hubbard V, Bray GA, Grunstein R, Hansen BC, Hong Y, Labarthe D, Seidell JC, Smith Jr SC. American Heart Association. Prevention Conference VII: Obesity, a Worldwide Epidemic Related to Heart Disease and Stroke: Group III: Worldwide Comorbidities of Obesity. Circulation 2004; 110: e476-e483.

22 McGuire HL, Svetkey LP, Harsha DW, Elmer PJ, Appel LJ, Ard JD. Comprehensive lifestyle modification and blood pressure control: a review of the PREMIER trial. J Clin Hypertens 2004; 6: 383-390.

23 Johnson AG, Nguyen TV, Davis D. Blood pressure is linked to salt intake and modulated by the angiotensinogen gene in normotensive and hypertensive elderly subjects. J Hypertens 2001; 19: 1053-1060.

24 Elliott P, Kesteloot H, Appel LJ, Dyer AR, Ueshima H, Chan Q, Brown IJ, Zhao L, Stamler J. INTERMAP Cooperative Research Group. Dietary phosphorus and blood pressure. International study of macro- and micro-nutrients and blood pressure. Hypertension 2008; 51: 669-675.

25 Schmieder R, Messerli F, Garagavlia G, Nunez B. Dietary salt intake: a determinant of cardiac involvement in essential hypertension. Circulation 1988; 78: 951-956.

26 Sacks FM, Svetkey LP, Vollmer WM, Appel LJ, Bray GA, Harsha D, Obarzanek E, Conlin PR, Miller III ER, Simons-Morton DG, Karanja N, Lin PH. DASH-Sodium Collaborative Research Group. Effects on blood pressure of reduced dietary sodium and the Dietary Approaches to Stop Hypertension (DASH) diet. DASH-Sodium Collaborative Research Group. N Eng/ J Med 2001; 344: 3-10.

27 The China Salt Substitute Study Collaborative Group. Salt substitution: a low-cost strategy for blood pressure control among rural Chinese. A randomized, controlled trial. J Hypertens 2007; 25: 2011-2018. 
28 Gu D, He J, Wu X, Duan X, Whelton PK. Effect of potassium supplementation on blood pressure in Chinese: a randomized, placebo-controlled trial. J Hypertens 2001; 19 : 1325-1331.

29 Karanja NM, Obarzanek E, Lin PH, McCullough ML, Phillips KM, Swain JF, Champagne CM, Hoben KP. Descriptive characteristics of the dietary patterns used in the Dietary Approaches to Stop Hypertension Trial. DASH Collaborative Research Group. Descriptive characteristics of the dietary patterns used in the Dietary Approaches to Stop Hypertension Trial. J Am Diet Assoc 1999; 99: S19-S27.

30 Vollmer WM, Sacks FM, Ard J, Appel LJ, Bray GA, Simons-Morton DG, Conlin PR, Svetkey LP, Erlinger TP, Moore TJ, Karanja N. DASH-Sodium Trial Collaborative Research Group. Effects of diet and sodium intake on blood pressure: subgroup analysis of the DASH-sodium trial. Ann Intern Med 2001; 135: 1019-1028.

31 Bray GA, Vollmer WM, Sacks FM, Obarzanek E, Svetkey LP, Appel LJ. DASH Collaborative Research Group. A further subgroup analysis of the effects of the DASH diet and three dietary sodium levels on blood pressure: results of the DASHSodium Trial. Am J Cardiol 2004; 94: 222-227.

32 Elliott P, Stamler J, Dyer AR, Appel L, Dennis B, Kesteloot H, Ueshima H, Okayama A Chan Q, Garside DB, Zhou B. Association between protein intake and blood pressure: The INTERMAP Study. Arch Intern Med 2006; 166: 79-87.

33 Appel LJ, Sacks FM, Carey VJ, Obarzanek E, Swain JF, Miller III ER, Conlin PR, Erlinger TP, Rosner BA, Laranjo NM, Charleston J, McCarron P, Bishop LM. OmniHeart Collaborative Research Group. Effects of protein, monounsaturated fat, and carbohydrate intake on blood pressure and serum lipids: results of the OmniHeart randomized trial. JAMA 2005; 294: 2455-2464.
34 Stamler J, Neaton JD. The Multiple Risk Factor Intervention Trial (MRFIT) Importance Then and Now. JAMA 2008; 300: 1343-1345.

35 Holmes E, Loo RL, Stamler J, Bictash M, Yap IK, Chan Q, Ebbels T, De lorio M, Brown IJ, Veselkov KA, Daviglus ML, Kesteloot H, Ueshima H, Zhao L, Nicholson JK, Elliott P. Human metabolic phenotype diversity and its association with diet and blood pressure. Nature 2008; 453: 396-400.

36 Elmer PJ, Obarzanek E, Vollmer WM, Simons-Morton D, Stevens VJ, Young DR, Lin PH, Champagne C, Harsha DW, Svetkey LP, Ard J, Brantley PJ, Proschan MA, Erlinger TP, Appel LJ. PREMIER Collaborative Research Group. Effects of comprehensive lifestyle modification on diet, weight, physical fitness, and blood pressure control: 18-month results of a randomized trial. Ann Intern Med 2006; 144: 485-495.

37 Svetkey LP, Erlinger TP, Vollmer WM, Feldstein A, Cooper LS, Appel LJ, Ard JD, Elmer PJ, Harsha D, Stevens VJ. Effect of lifestyle modifications on blood pressure by race, sex, hypertension status, and age. J Hum Hypertens 2005; 19: 21-31.

38 Stehman-Breen CO, Gillen D, Steffes M, Jacobs Jr DR, Lewis CE, Kiefe CI, Siscovick D. Racial Differences in Early-Onset Renal Disease among Young Adults: The Coronary Artery Risk Development in Young Adults (CARDIA) Study. J Am Soc Nephrol 2003; 14: 2352-2357.

39 Mahaney M, Blangero J, Comuzzie A, VandeBerg JL, Stern MP, MacCluer JW. Plasma HDL cholesterol, triglycerides, and adiposity. A quantitative genetic test of the conjoint trait hypothesis in the San Antonio Family Heart Study. Circulation 1995; 92: $3240-3248$ 